\title{
An Improved Finite-Control-Set Model Predictive Current Control for IPMSM under Model Parameter Mismatches
}

\author{
Zehao Lyu, Xiang Wu * $\mathbb{C}$, Jie Gao and Guojun Tan *
}

Citation: Lyu, Z.; Wu, X.; Gao, J.; Tan, G. An Improved

Finite-Control-Set Model Predictive Current Control for IPMSM under Model Parameter Mismatches. Energies 2021, 14, 6342. https:// doi.org/10.3390/en14196342

Academic Editors: Vitor Monteiro and Adolfo Dannier

Received: 3 August 2021

Accepted: 30 September 2021

Published: 4 October 2021

Publisher's Note: MDPI stays neutral with regard to jurisdictional claims in published maps and institutional affiliations.

Copyright: (c) 2021 by the authors. Licensee MDPI, Basel, Switzerland. This article is an open access article distributed under the terms and conditions of the Creative Commons Attribution (CC BY) license (https:// creativecommons.org/licenses/by/ $4.0 /)$.
School of Electrical and Power Engineering, China University of Mining and Technology, Xuzhou 221000, China; zjjxphlzh@163.com (Z.L.); Gaojie1@cumt.edu.cn (J.G.)

* Correspondence: wux@cumt.edu.cn (X.W.); gjtan_cumt@163.com (G.T.); Tel.: +86-151-0521-2760 (X.W.); +86-138-0521-9335 (G.T.)

\begin{abstract}
The control performance of the finite control set model predictive current control (FCSMPCC) for the interior permanent magnet synchronous machine (IPMSM) depends on the accuracy of the mathematical model. A novel robust model predictive current control method based on error compensation is proposed in order to reduce the parameter sensitivity and improve the current control robustness. In this method, the equivalent parameters are obtained from the known voltage and current information at the past time and the error between the predicted current and the actual current at the present time, which is utilized in the two-step prediction process to compensate the parameter mismatch error. Finally, the optimal voltage vector is selected by the cost function. The proposed method is compared with the traditional model predictive current control method through experiments. The experimental results show the effectiveness of the proposed method.
\end{abstract}

Keywords: permanent magnet synchronous motor; predictive current control; parameter mismatch

\section{Introduction}

Permanent magnet synchronous motor (PMSM) has been widely used in the field of high-performance power transmission and renewable energy generation [1] owing to the advantages of simple structure, reliable operation, high power density and high efficiency. Different control algorithms of PMSM are studied for achieving different control objectives, such as field oriented control (FOC) [2], direct torque control (DTC) [3,4], fuzzy control [5], nonlinear control [6] and model predictive control (MPC) [7-18].

In recent years, the MPC method utilized in permanent magnet synchronous motor has been widely concerned by scholars because of fast dynamic response. Besides, the MPC method can deal with different system constraints at the same time [7]. MPC can be divided into two categories. One is continuous control set MPC (CCS-MPC) and the other is finite control set MPC (FCS-MPC) [8]. Compared with CCS-MPC, the structure of FCS-MPC is simpler because it does not need PWM. In FCS-MPC, the future values of the state variable are predicted to track the reference value in each period and the voltage vector of the inverter which minimizes the tracking error is selected [9]. The finite control set model predictive current control (FCS-MPCC) method takes the current as the control object without current loop PI regulation. This paper focus on the FCS-MPCC method.

Scholars have proposed some new methods to improve the control performance of conventional FCS-MPCC with different targets. In [10], a new prediction model in the continuous-time domain is proposed to replace the linear discretization model. The new model is built to improve the control accuracy at low frequency. In [11], a novel method is proposed to compensate the delay time of the system by the relationship between the current variation and the delay time. It only needs one-step prediction in each period with the new method compared with the conventional two-step prediction. In [12], a new FCS-MPCC with common-mode voltage constraint is proposed in order to suppress the negative effects result from the common-mode voltage generated by the inverter. In [13], 
a new method with low computational burden is proposed to simplify the calculation in dual-vector MPC with reducing the number of candidate active voltage vectors.

In addition, there is another problem in FCS-MPCC that cannot be ignored. FCS-MPCC is a control method based on motor mathematical model, thus, its control performance is affected by motor parameters. When the motor runs for a long time and the parameters change, the current will be distorted, which causes steady-state error and decline of system control performance. Therefore, it is worth studying to reduce the sensitivity to parameters of FCS-MPC to improve the current control performance. Some scholars have proposed some solutions to this problem. In [14], a new cost function in the form of proportional integral is proposed, which not only reduces the current steady-state error, but also reduces the parameter sensitivity. In [15], a parameter identification algorithm is proposed to get the actual parameter value. The prediction accuracy is improved with the updated parameter in real time. In [16], the conventional mathematical model is replaced by the measured data, and a parameter-free predictive control method is proposed, which eliminates the relationship between the prediction process and the model parameters.

The parameter mismatch disturbance can also be eliminated by observer approaches. At present, the observer approach is mainly applied to deadbeat model predictive control (DB-MPC) [17,18], explicit model predictive control (EMPC) [19] and nonlinear model predictive control [20], and there is little research about the observer applied to finite control set model predictive control (FCS-MPC). In [17], a Luenberger observer for DBMPC is proposed to eliminate disturbance and noise against parameter mismatch. There are two observer gains affecting the bandwidth, which need to be chosen reasonably. In [18], a novel current and disturbance observer with proportional-differential type iterative learning control and sliding-mode control for DB-MPC is proposed to suppress the periodic disturbances and parameter disturbances simultaneously. However, ten parameters need to be selected appropriately, which increases the complexity of the system. In [19], an adaptive Kalman observer is proposed to estimate total disturbance within the closed-loop framework of EMPC. It can achieve a stable closed-loop system for zero steady-state offset even if parameter mismatch exists. Compared with the non-observer method, it needs to select appropriate coefficient matrixes and matrix calculation, and the workload is larger. In [20], the parameter variations are considered as disturbances. Then a sliding mode observer and a Luenberger observer are designed to estimate the disturbance to reduce the current error. Although good control effect is achieved, the system design is complex.

A robust FCS-MPC approach based on proportional-integral observer is proposed in [21] and the research object is the induction motor (IM). Due to the high computational complexity, the one-step prediction is performed. One advantage of the observer approach is that it can also resist other disturbances not only the parameter mismatch by observing the lumped disturbance with the stator current prediction error. One drawback of observer approach is that it cannot accurately compensate the one-step delay. Because the current prediction error at $k+1$ instant cannot be obtained from the sampling current at $k$ instant. Then it is hard to predict the stator current at $k+2$ instant precisely when there exists the one-step delay in the digital system. In this situation, the predicted current estimated by the observer is used for replacing the sampled current in the observer approach. The observer approach is mainly applied to the MPC with voltage modulation such as DB-MPC and EMPC with only one-step prediction. The observer approach often requires adjusting multiple coefficients.

At present, most of the researches about parameter mismatch of FCS-MPCC take the surface-mounted permanent magnet synchronous motor (SPMSM) as the research object. However, the $d$-axis inductance and $q$-axis inductance of the interior permanent magnet synchronous motor (IPMSM) are different because of the structure, and the mathematical model of IPMSM is more complex than that of the surface-mounted permanent magnet synchronous motor. Therefore, for IPMSM, a robust model predictive current control method based on current error compensation is proposed in this paper. The current error is obtained by the predicted current and the actual current. The relationship between the 
current error and parameter mismatch is constructed by using the mathematical model. Then the parameter mismatch parameters are obtained by using the known information in the past two cycles, which is utilized in the prediction process of the next cycle as the compensation quantity. Finally, experiments of the proposed method and the conventional method are carried out on an IPMSM. The experimental results show that the proposed method can effectively reduce the sensitivity to parameters of FCS-MPCC.

\section{Conventional Model Predictive Current Control of IPMSM}

To simplify the mathematical model, some assumptions are made in this paper, including (1) the magnetic saturation is negligible, (2) the magnetic hysteresis loss, core loss and eddy current loss are little effect and (3) the three-phase winding of the machine is symmetrical. The mathematical model of IPMSM in the synchronous rotating frame is shown as Equation (1):

$$
\left\{\begin{array}{l}
\frac{d i_{d}}{d t}=-\frac{\hat{R}_{s}}{\hat{L}_{d}} i_{d}+\frac{\hat{L}_{q}}{\hat{L}_{d}} \omega_{e} i_{q}+\frac{1}{\hat{L}_{d}} u_{d} \\
\frac{d i_{q}}{d t}=-\frac{\hat{R}_{s}}{\hat{L}_{q}} i_{q}-\frac{\hat{L}_{d}}{\hat{L}_{q}} \omega_{e} i_{d}-\frac{\hat{\psi}_{f}}{\hat{L}_{q}} \omega_{e}+\frac{1}{\hat{L}_{q}} u_{q}
\end{array}\right.
$$

where $u_{d}, u_{q}$ are the $d$-axis and $q$-axis stator voltages, respectively, $i_{d}, i_{q}$ are the $d$-axis and $q$-axis stator currents, respectively, $L_{d}, L_{q}$ are the $d$-axis and $q$-axis stator inductance, respectively, $R_{S}$ is the stator resistance, $\Psi_{f}$ is the permanent magnet flux linkage and $\omega_{e}$ is rotor electrical angular velocity, and the symbol " ${ }^{\prime \prime}$ indicates the nominal value.

By forward Euler discretization of Equation (1) at $k$ instant, the current prediction equation at $k+1$ instant can be obtained as Equation (2):

$$
\left\{\begin{array}{l}
i_{d}^{p}(k+1)=\hat{A}_{1} i_{d}(k)+\hat{A}_{2} \omega_{e}(k) i_{q}(k)+\hat{A}_{3} u_{d}(k) \\
i_{q}^{p}(k+1)=\hat{B}_{1} i_{q}(k)-\hat{B}_{2} \omega_{e}(k) i_{d}(k)+\hat{B}_{3} u_{q}(k)-\hat{B}_{4} \omega_{e}(k)
\end{array}\right.
$$

where $\hat{A}_{1}=1-\hat{R}_{s} T_{s} / \hat{L}_{d}, \hat{A}_{2}=\hat{L}_{q} T_{s} / \hat{L}_{d}, \hat{A}_{3}=T_{s} / \hat{L}_{d}, \hat{B}_{1}=1-\hat{R}_{s} T_{s} / \hat{L}_{q}, \hat{B}_{2}=\hat{L}_{d} T_{s} / \hat{L}_{q}$, $\hat{B}_{3}=T_{s} / \hat{L}_{q}, \hat{B}_{4}=\hat{\psi}_{f} T_{s} / \hat{L}_{q}, T_{s}$ is the sample period, $k$ is the sample instant, and the superscript ' $p$ ' indicates the predictive value.

Ideally, the optimal voltage vector calculated at $k$ instant can be applied in time at the current period to obtain the accurate predicted current at $k+1$ instant. However, due to the system delay, the optimal voltage vector at $k$ instant may be used after $k+1$ instant, and the optimal voltage vector needed at $k+1$ instant may be different from the optimal voltage vector at $k$ instant, resulting in undesirable current control effect. Two step prediction method is usually used in order to compensate the system delay. Firstly, the first step prediction is performed through Equation (2) to obtain the predicted current at $k+1$ instant, where the optimal voltage vector at $k$ instant is already obtained from last period. Then the second step prediction is performed by Equation (3):

$$
\left\{\begin{array}{l}
i_{d}^{p}(k+2)=\hat{A}_{1} i_{d}(k+1)+\hat{A}_{2} \omega_{e}(k+1) i_{q}(k+1)+\hat{A}_{3} U_{d n}(k+1) \\
i_{q}^{p}(k+2)=\hat{B}_{1} i_{q}(k+1)-\hat{B}_{2} \omega_{e}(k+1) i_{d}(k+1)+\hat{B}_{3} U_{q n}(k+1)-\hat{B}_{4} \omega_{e}(k+1)
\end{array}\right.
$$

where $U_{d n}, U_{q n}$ are the $d$-axis and $q$-axis components of basic voltage vectors, respectively, which can be output by the inverter, and $n=0,1,2, \ldots 7$. There are 8 kinds of basic voltage vectors of two-level inverter, including two zero vectors and six non-zero vectors.

In the end, eight groups of predicted currents at $k+2$ instant obtained by Equation (3) are substituted into the following cost function (4):

$$
J=\left[i_{d}^{*}-i_{d}^{p}(k+2)\right]^{2}+\left[i_{q}^{*}-i_{q}^{p}(k+2)\right]^{2}
$$

where $i_{d}^{*}, i_{q}^{*}$ are the $d$-axis and $q$-axis reference currents, respectively. The voltage vector that minimizes the value of the cost function is the selected optimal voltage vector.

\section{Parameter Mismatch Analysis of FCS-MPCC}

In the conventional FCS-MPCC, the motor parameters in the mathematical model used in the prediction process are unchanged. During the actual operation of the motor, 
the motor parameters will change due to temperature rise, magnetic field change and other factors, which is called parameter mismatch. Equation (2) is the first step prediction process using the nominal parameters. If the parameters are the actual value at the current instant, the accurate first step prediction process is shown as follows:

$$
\left\{\begin{array}{l}
i_{d}(k+1)=A_{1} i_{d}(k)+A_{2} \omega_{e}(k) i_{q}(k)+A_{3} u_{d}(k) \\
i_{q}(k+1)=B_{1} i_{q}(k)-B_{2} \omega_{e}(k) i_{d}(k)+B_{3} u_{q}(k)-B_{4} \omega_{e}(k)
\end{array}\right.
$$

where $A_{1}=1-R_{s} T_{s} / L_{d}, A_{2}=L_{q} T_{s} / L_{d}, A_{3}=T_{s} / L_{d}, B_{1}=1-R_{s} T_{s} / L_{q}, B_{2}=L_{d} T_{s} / L_{q}$, $B_{3}=T_{s} / L_{q}$, and $B_{4}=\psi_{f} T_{s} / L_{q}$.

The current prediction error at $k+1$ instant can be obtained by subtracting Equation (2) from Equation (5) as:

$$
\left\{\begin{array}{l}
e_{d}(k+1)=i_{d}(k+1)-i_{d}^{p}(k+1)=\Delta A_{1} i_{d}(k)+\Delta A_{2} \omega_{e}(k) i_{q}(k)+\Delta A_{3} u_{d}(k) \\
e_{q}(k+1)=i_{q}(k+1)-i_{q}^{p}(k+1)=\Delta B_{1} i_{q}(k)-\Delta B_{2} \omega_{e}(k) i_{d}(k)+\Delta B_{3} u_{q}(k)-\Delta B_{4} \omega_{e}(k)
\end{array}\right.
$$

where $\Delta A_{1}=\hat{R}_{s} T_{s} / \hat{L}_{d}-R_{s} T_{s} / L_{d}, \Delta A_{2}=L_{q} T_{s} / L_{d}-\hat{L}_{q} T_{s} / \hat{L}_{d}, \Delta A_{3}=T_{s} / L_{d}-T_{s} / \hat{L}_{d}$, $\Delta B_{1}=\hat{R}_{s} T_{s} / \hat{L}_{q}-R_{s} T_{s} / L_{q}, \Delta B_{2}=L_{d} T_{s} / L_{q}-\hat{L}_{d} T_{s} / \hat{L}_{q}, \Delta B_{3}=T_{s} / L_{q}-T_{s} / \hat{L}_{q}, \Delta B_{4}=$ $\psi_{f} T_{s} / L_{q}-\hat{\psi}_{f} T_{s} / \hat{L}_{q}$, and $e$ is the current prediction error.

It can be seen from Equation (6) that because of parameter mismatch, there will be current prediction error in the first prediction process, and the expected predicted current at $k+1$ instant cannot be obtained. Because there are two steps in the prediction process, when using the $k+1$ instant prediction current with error for the second prediction, it will further affect the prediction process and lead to inaccurate selection of voltage vector.

\section{The Proposed Robust FCS-MPCC}

The current control performance of the conventional FCS-MPCC is deteriorated due to parameter mismatch. Therefore, a robust model predictive current control method based on error compensation is proposed. The schematic diagram of the robust FCS-MPCC is shown in Figure 1.

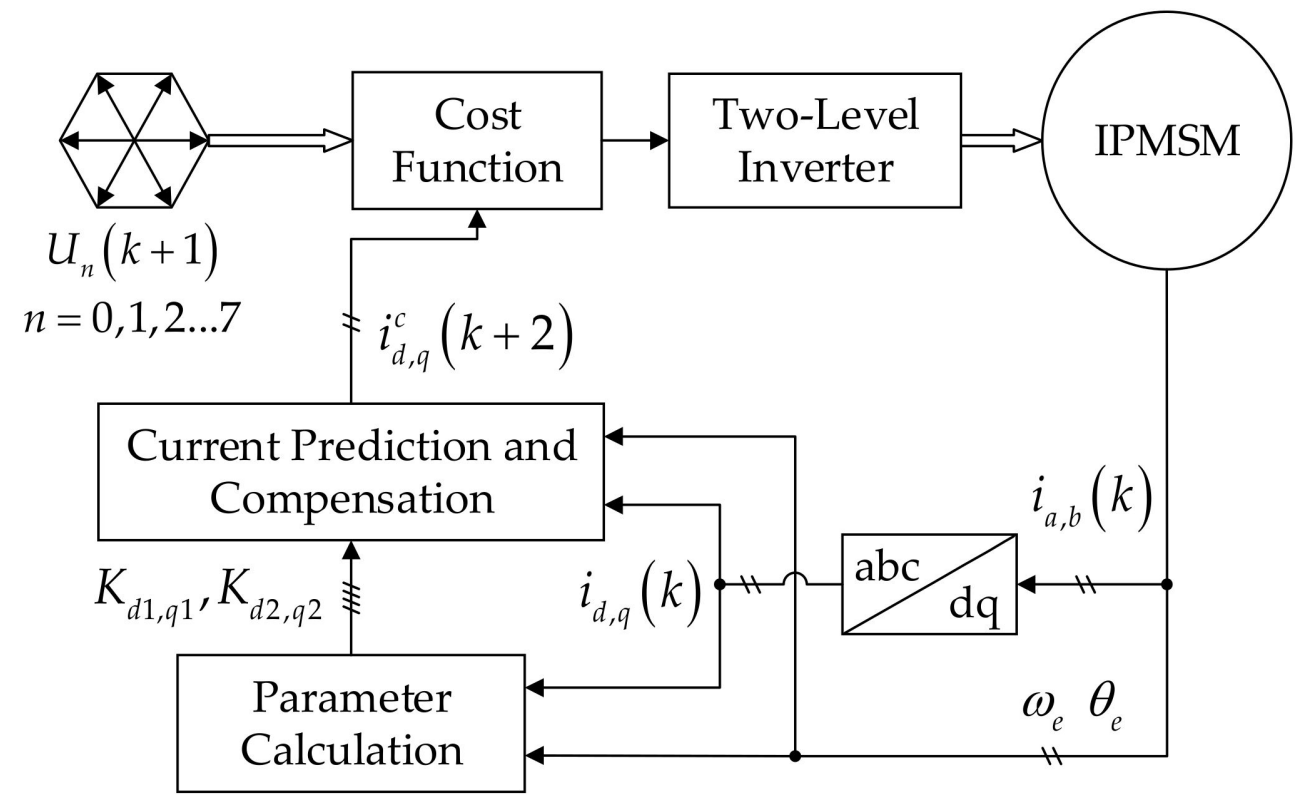

Figure 1. The schematic diagram of the robust FCS-MPCC.

\subsection{Parameter Calculation}

It can be seen from Equation (6) that the current prediction error contains parameter mismatch information i.e., $\Delta A_{1}, \Delta A_{2}, \Delta A_{3}, \Delta B_{1}, \Delta B_{2}, \Delta B_{3}$ and $\Delta B_{4}$. The unit level of stator inductance of IPMSM is $\mathrm{mH}$, and the stator resistance is often less than $1 \Omega$ so that $\Delta A_{1}$ can be considered less than $\Delta A_{3}, \Delta B_{1}$ can be considered less than $\Delta B_{3}$ as well. Moreover, in the steady state, the current tends to be stable, and the voltage vector is still selected in 
each sampling period. The influence of current change is less than that of voltage change. The quadrature component of a specific voltage vector is related to the rotor position. The variation frequency of the rotor position is proportional to rotor electrical angular velocity, which is much less than the sampling frequency. Thus, $\Delta A_{2} \omega_{e} i_{q}$ can be considered less than $\Delta A_{3} u_{d}$ and $\Delta B_{2} \omega_{e}$ can be considered less than $\Delta B_{3} u_{q}$. In a word, the first two terms on the right side of Equation (6) can be ignored compared with the third term. Equation (6) can be simplified as:

$$
\left\{\begin{array}{l}
e_{d}(k+1) \approx \Delta A_{3} u_{d}(k) \\
e_{q}(k+1) \approx \Delta B_{3} u_{q}(k)-\Delta B_{4} \omega_{e}(k)
\end{array}\right.
$$

Since the mechanical time constant of the motor is much larger than the electrical time constant, it can be considered that the rotor electrical angular velocity in the adjacent two periods is equal, such as $\omega_{e}(k-1) \approx \omega_{e}(k-2)$. According to the above analysis, the difference of the current prediction error between $k$ instant and $k-1$ instant can be obtained by:

$$
\left\{\begin{array}{l}
e_{d}(k)-e_{d}(k-1)=K_{d 1}\left[u_{d}(k-1)-u_{d}(k-2)\right] \\
e_{q}(k)-e_{q}(k-1)=K_{q 1}\left[u_{q}(k-1)-u_{q}(k-2)\right]
\end{array}\right.
$$

where $K_{d 1}=T_{s} / L_{d}-T_{s} / \hat{L}_{d}, K_{q 1}=T_{s} / L_{q}-T_{s} / \hat{L}_{q}$.

The $d$-axis and $q$-axis currents, $d$-axis and $q$-axis voltages and rotor angular velocity at $k$ instant can be obtained by sampling. Then the current prediction error at $k$ instant can be calculated. Besides, the correlation quantities of $k-1$ instant and $k-2$ instant are already known so that the parameters $K_{d 1}$ and $K_{q 1}$ can be calculated by:

$$
\left\{\begin{array}{l}
K_{d 1}=\left[e_{d}(k)-e_{d}(k-1)\right] /\left[u_{d}(k-1)-u_{d}(k-2)\right] \\
K_{q 1}=\left[e_{q}(k)-e_{q}(k-1)\right] /\left[u_{q}(k-1)-u_{q}(k-2)\right]
\end{array}\right.
$$

Then the current prediction error at $k$ instant can be expressed as

$$
\left\{\begin{array}{l}
e_{d}(k)=\Delta A_{1} i_{d}(k-1)+\Delta A_{2} \omega_{e}(k-1) i_{q}(k-1)+K_{d 1} u_{d}(k-1) \\
e_{q}(k)=\Delta B_{1} i_{q}(k-1)-\Delta B_{2} \omega_{e}(k-1) i_{d}(k-1)-\Delta B_{4} \omega_{e}(k-1)+K_{q 1} u_{q}(k-1)
\end{array}\right.
$$

Define the parameters $K_{d 2}$ and $K_{q 2}$ as:

$$
\left\{\begin{array}{l}
K_{d 2}=\Delta A_{1} i_{d}(k-1)+\Delta A_{2} \omega_{e}(k-1) i_{q}(k-1) \\
K_{q 2}=\Delta B_{1} i_{q}(k-1)-\Delta B_{2} \omega_{e}(k-1) i_{d}(k-1)-\Delta B_{4} \omega_{e}(k-1)
\end{array}\right.
$$

They can be obtained by combining Equations (10) and (11) as:

$$
\left\{\begin{array}{l}
K_{d 2}=e_{d}(k)-K_{d 1} u_{d}(k-1) \\
K_{q 2}=e_{q}(k)-K_{q 1} u_{q}(k-1)
\end{array}\right.
$$

\subsection{Prediction Process Based on Error Compensation}

Firstly, the parameters calculated in the previous section are filtered by a low-pass filter. A common first-order low-pass filter is selected to reduce the burr of the parameters. The filtering effect is realized by software both in the simulation and experiments. The algorithm of the first-order low-pass filter is shown as:

$$
y(k)=a x(k)+(1-a) y(k-1)
$$

where $y(k)$ is the filtering result at $k$ instant, $y(k-1)$ is the filtering result at $k-1$ instant, $x(k)$ is the input value of the filter at $k$ instant and $a$ is the filter coefficient which is between 0 to 1 . It is necessary to select appropriate filter coefficient to obtain good filtering effect by observing the waveforms of the parameters. The selection process is very simple and not be discussed here.

Then they are substituted into the first prediction process to compensate the current prediction error, which is obtained by combining Equations (2) and (6) as:

$$
\left\{\begin{array}{l}
i_{d}^{c}(k+1)=i_{d}^{p}(k+1)+e_{d}(k+1)=i_{d}^{p}(k+1)+K_{d 2}+K_{d 1} u_{d}(k) \\
i_{q}^{c}(k+1)=i_{q}^{p}(k+1)+e_{q}(k+1)=i_{q}^{p}(k+1)+K_{q 2}+K_{q 1} u_{q}(k)
\end{array}\right.
$$

where the superscript ' $c$ ' indicates the current after compensation. 
The compensated $k+1$ instant current is used for the second prediction with the parameters for compensation like the first prediction. The second prediction equation with compensation is shown as:

$$
\left\{\begin{aligned}
i_{d}^{c}(k+2)= & \hat{A}_{1} i_{d}^{p}(k+1)+\hat{A}_{2} \omega_{e}(k+1) i_{q}^{p}(k+1)+\hat{A}_{3} U_{d n}(k+1) \\
& +K_{d 2}+K_{d 1} U_{d n}(k+1) \\
i_{q}^{c}(k+2)= & \hat{B}_{1} i_{q}^{p}(k+1)-\hat{B}_{2} \omega_{e}(k+1) i_{d}^{p}(k+1)+\hat{B}_{3} U_{q n}(k+1)-\hat{B}_{4} \omega_{e}(k+1) \\
& +K_{q 2}+K_{q 1} U_{q n}(k+1)
\end{aligned}\right.
$$

In the end, the optimal voltage vector is selected by the new cost function (16):

$$
J=\left[i_{d}^{*}-i_{d}^{c}(k+2)\right]^{2}+\left[i_{q}^{*}-i_{q}^{c}(k+2)\right]^{2}
$$

The flowchart of the proposed MPC is shown in Figure 2.

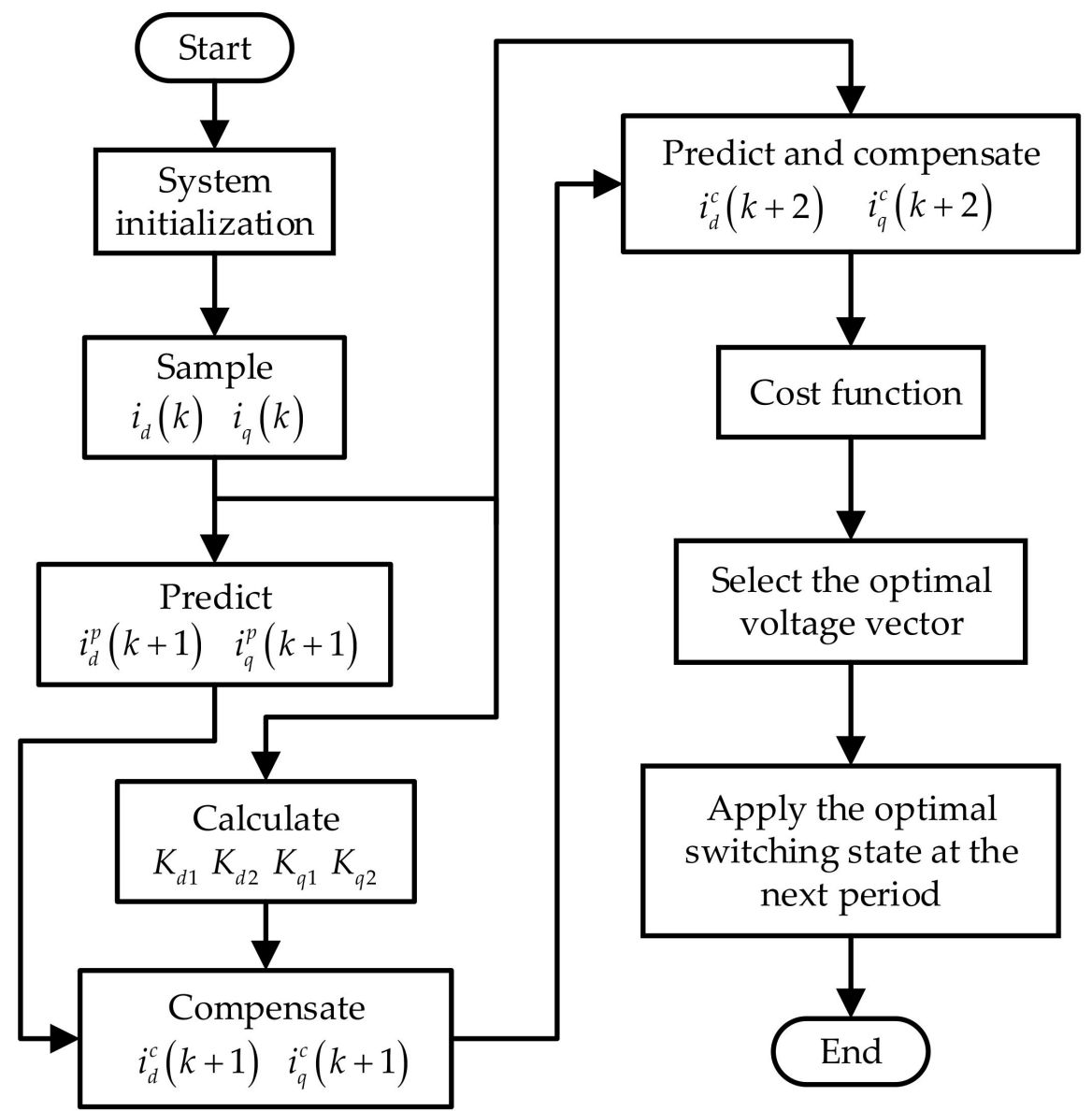

Figure 2. The flowchart of the proposed MPC.

\section{Simulation and Experimental Verification}

In order to validate the effectiveness of the proposed method, the comparative simulation of the conventional FCS-MPCC and the robust FCS-MPCC under parameter mismatch is carried out in the MATLAB/Simulink environment. The main parameters of the IPMSM used in the simulation is shown in Table 1 . The sample period is set to $100 \mu \mathrm{s}$. The speed of the motor is $900 \mathrm{r} / \mathrm{min}$ and the load torque is $40 \mathrm{~N} / \mathrm{m}$. The filtering coefficient $a$ is set to 0.01 both in the simulation and experiments. The $q$-axis current reference value is obtained from the output of PI regulator of speed loop, and the $d$-axis current reference value is set to 0 . The conventional FCS-MPCC is recorded as method 1, and the robust FCS-MPCC is recorded as method 2 . 
Table 1. Parameters of the IPMSM.

\begin{tabular}{cc}
\hline Parameter & Value \\
\hline Stator resistance & $0.1 \Omega$ \\
$d$-axis stator inductance & $0.95 \mathrm{mH}$ \\
$q$-axis stator inductance & $2.05 \mathrm{mH}$ \\
flux linkage & $0.225 \mathrm{~Wb}$ \\
Pole pairs & 4 \\
DC bus voltage & $310 \mathrm{~V}$ \\
\hline
\end{tabular}

Figure 3 shows the $d$-axis and $q$-axis current waveforms of the motor corresponding to the two methods in steady state under resistance mismatch, where $R_{s}=3 \hat{R}_{s}$. As can be seen from Figure 3, the current control performance of FCS-MPCC is little affected by resistance mismatch because the term related to resistance is much small compared to other terms in Equation (5).

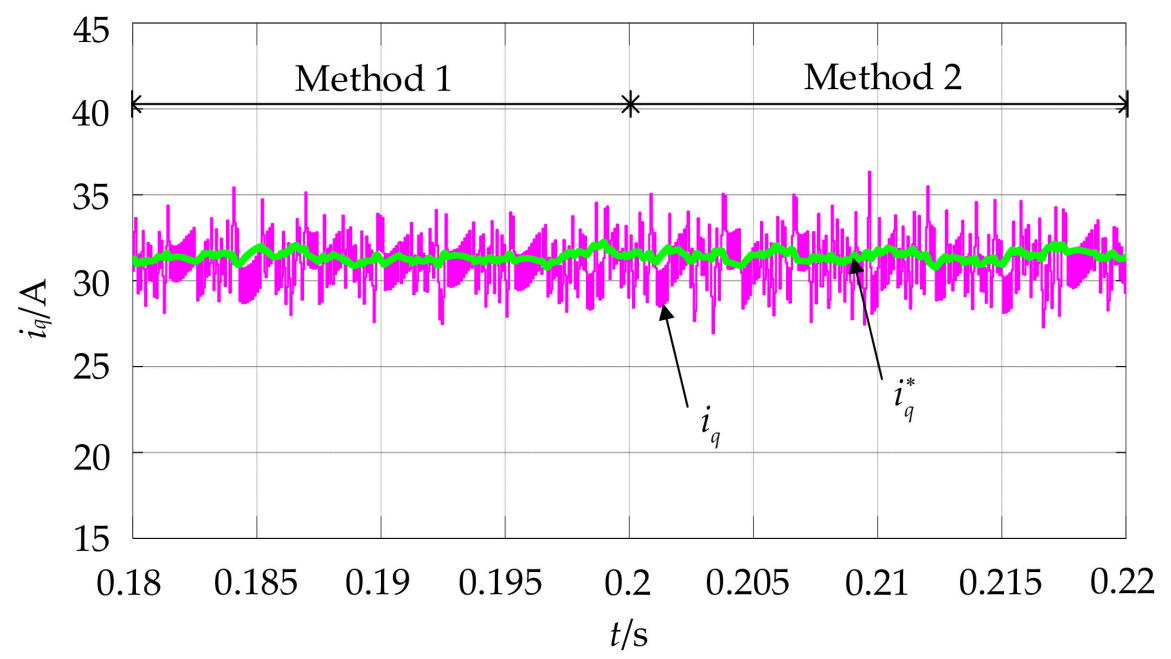

(a)

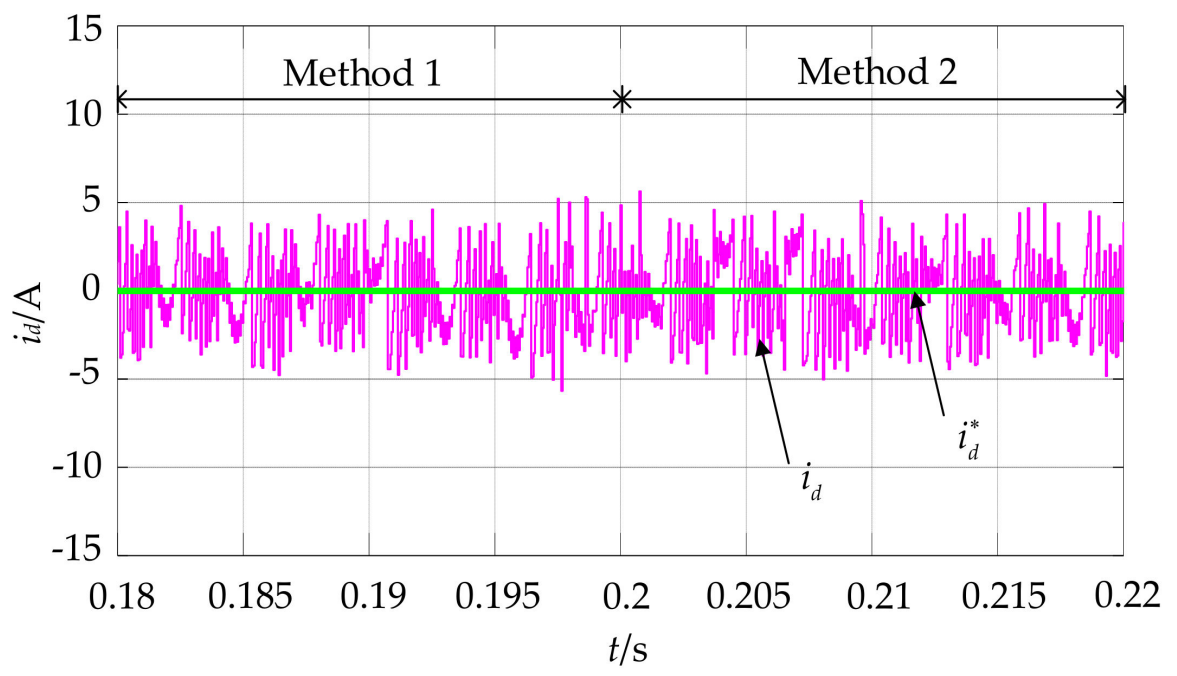

(b)

Figure 3. The current response of the two methods under resistance mismatch. (a) $q$-axis current; (b) $d$-axis current. 
The current response under flux linkage mismatch is also observed, which is shown in Figure 4 , where $\psi_{f}=2 \hat{\psi}_{f}$. According to the mathematical model of the motor, it can be found that the flux linkage only appears in the $q$-axis equation. When the flux linkage changes, the $q$-axis current mismatch occurs between the actual value and the reference value while the $d$-axis current is less affected. Figure 4 shows the nice current control performance of the robust FCS-MPCC.

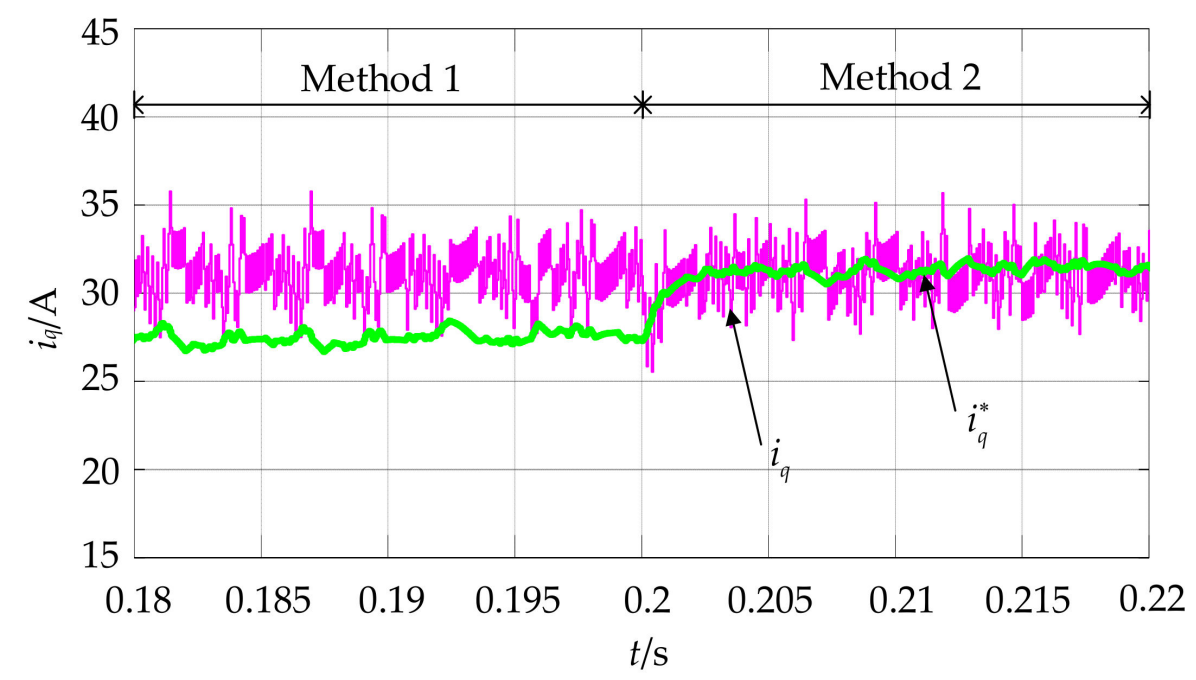

(a)

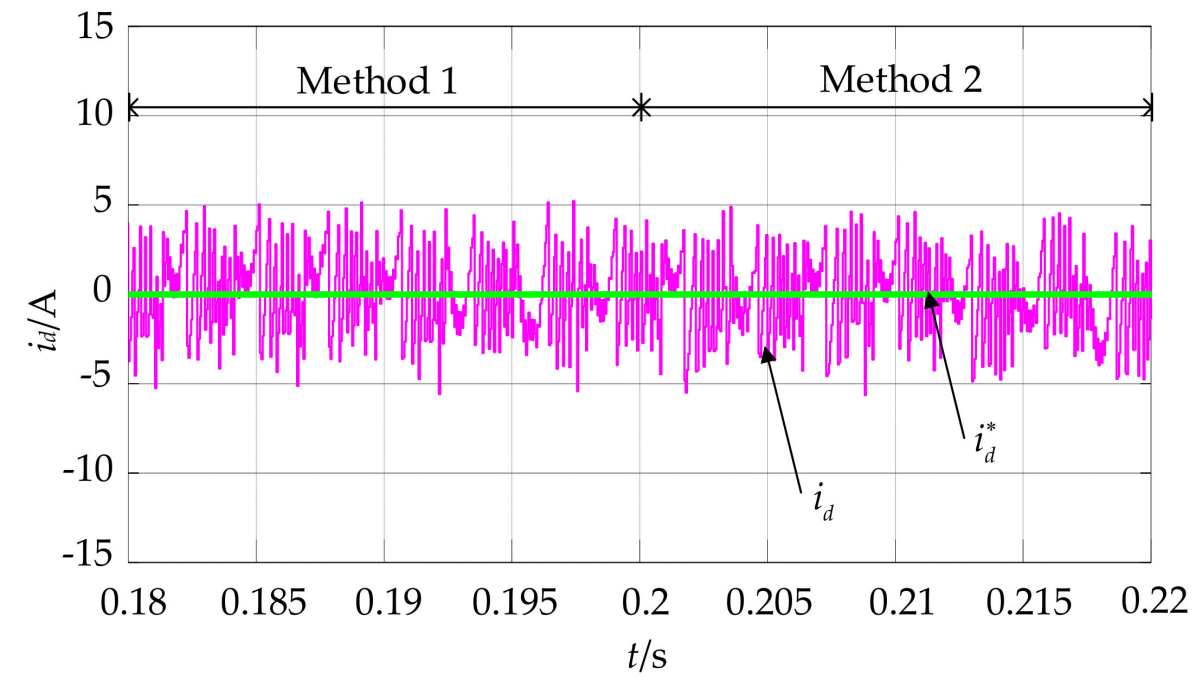

(b)

Figure 4. The current response of the two methods under flux linkage mismatch. (a) $q$-axis current; (b) $d$-axis current.

The current response under inductance mismatch are shown in Figure 5, where $L_{d}=1.5 \hat{L}_{d}, L_{q}=3 \hat{L}_{q}$. Both the $q$-axis current and $d$-axis current cannot track the reference current. Compared with the resistance mismatch and flux linkage mismatch, the current waveform under inductance mismatch is the worst. In these three cases, the robust FCSMPCC can achieve good control effect. 


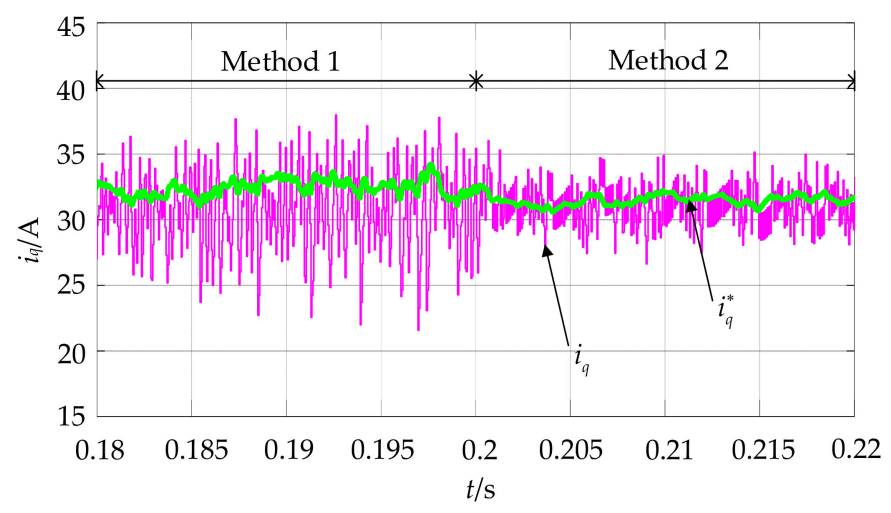

(a)

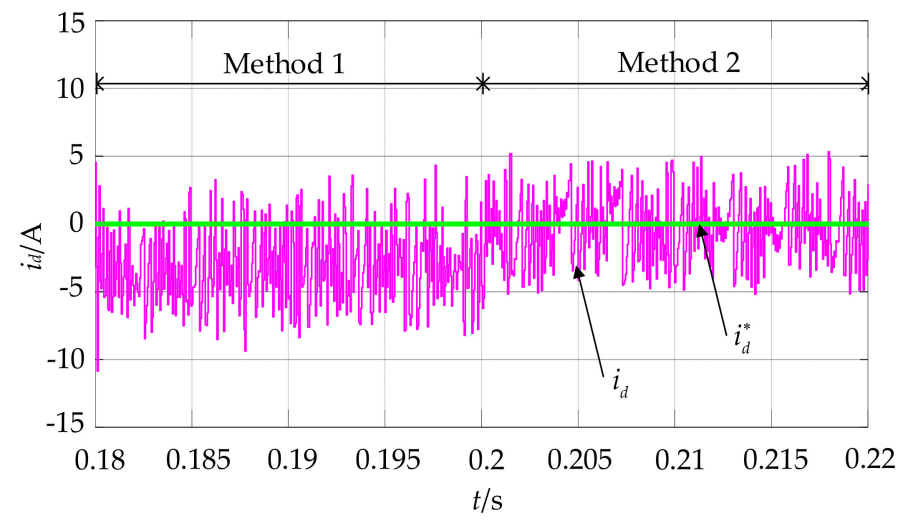

(b)

Figure 5. The current response of the two methods under inductance mismatch. (a) $q$-axis current; (b) $d$-axis current.

In the end, the comparative experiments of the two methods are conducted. The experimental platform is shown in Figure 6, which mainly concludes one rectifier, two inverters, one test IPMSM and one load IPMSM, one pulse board and three controllers. The parameters of the test IPMSM is same as the parameters in the simulation. The sample period is set to $60 \mu \mathrm{s}$ in the experiments. The speed of the motor is $900 \mathrm{r} / \mathrm{min}$ and the load torque is about $67 \mathrm{~N} / \mathrm{m}$.

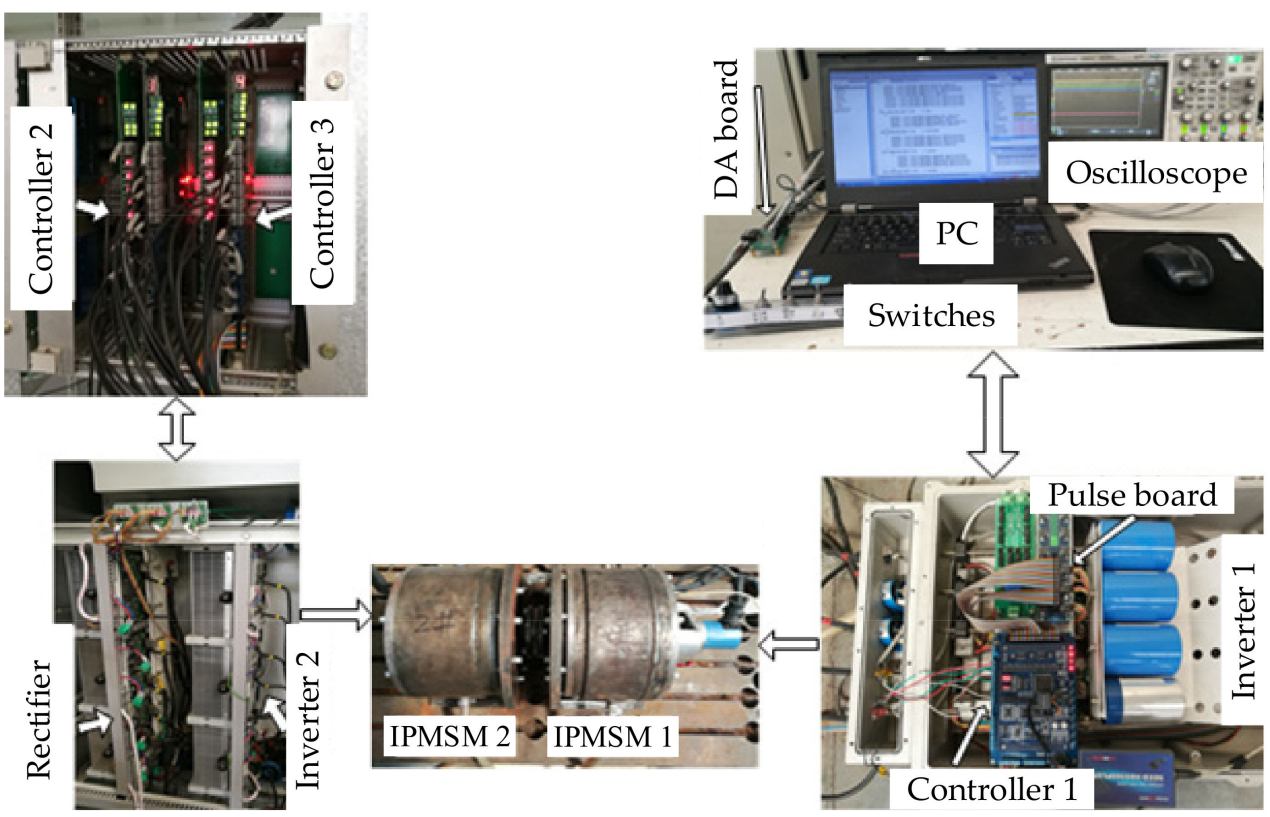

Figure 6. The experimental platform.

Figure 7 shows the current response in steady state of the two methods under full parameter mismatch, where $R_{s}=3 \hat{R}_{s}, L_{d}=1.5 \hat{L}_{d}, L_{q}=3 \hat{L}_{q}, \psi_{f}=2 \hat{\psi}_{f}$. It can be found that the current control performance of the conventional FCS-MPCC deteriorates under parameter mismatch. The actual current fails to track the reference current precisely with large current ripple, and the phase-a current is distorted. Conversely, the robust FCS-MPCC can effectively reduce the current ripple, reduce the steady state error, improve the tracking accuracy and make the phase current smoother. 


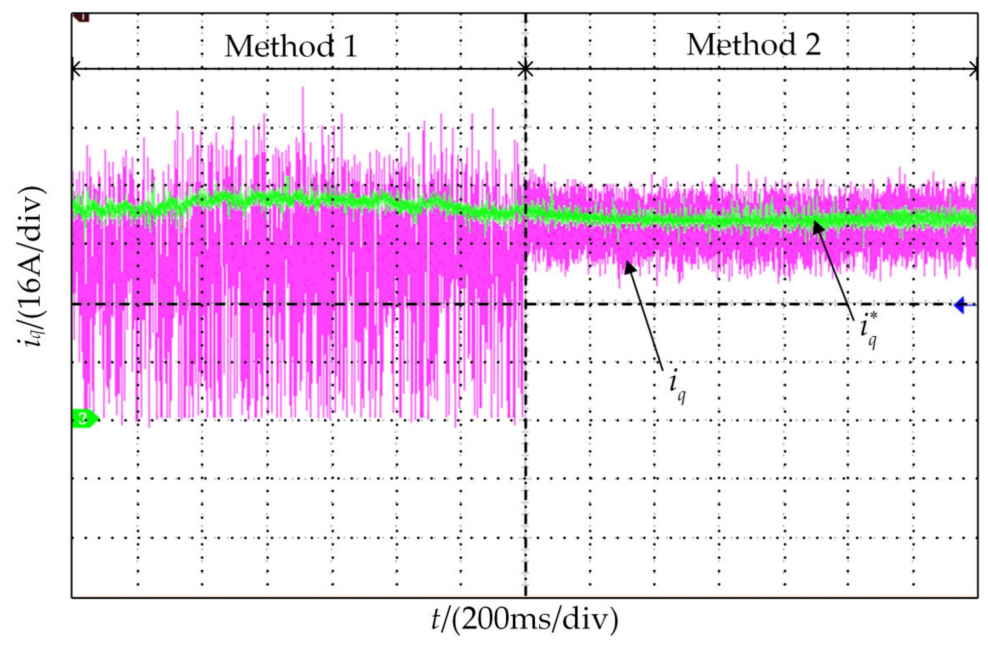

(a)

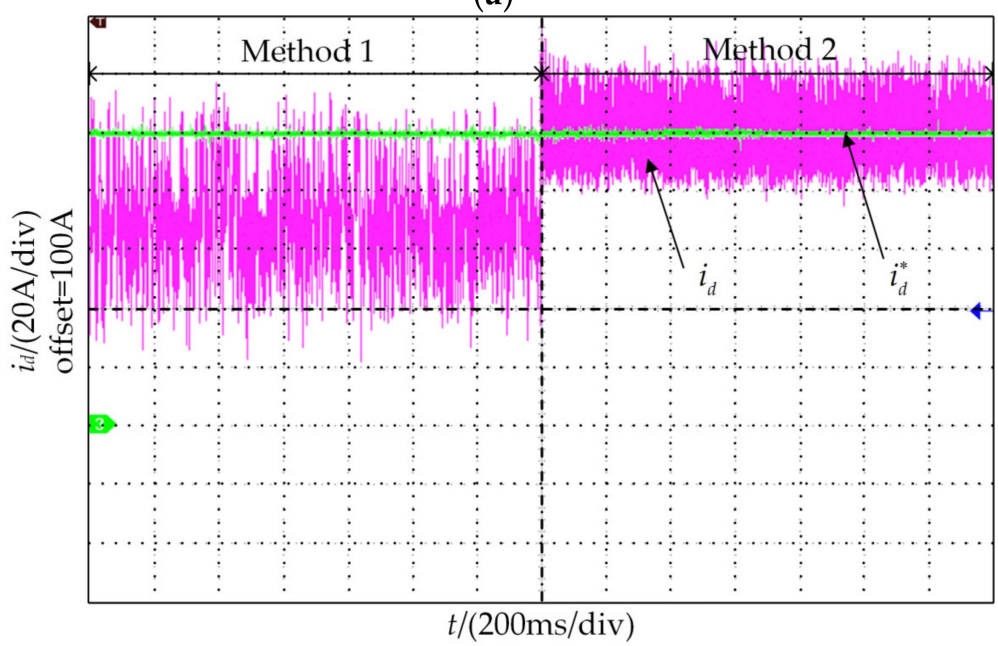

(b)

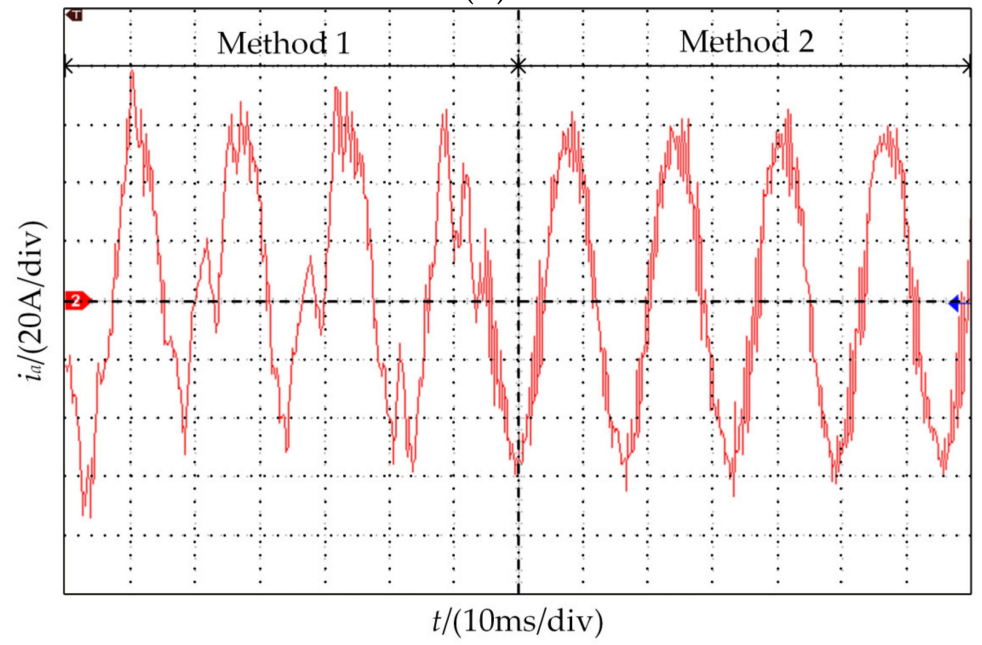

(c)

Figure 7. The current response in steady state of the two methods under parameter mismatch. (a) $q$-axis current; (b) $d$-axis current; (c) phase-a current.

In Figure 8, the speed and current transient responses of the robust FCS-MPCC under parameter mismatch is observed. The situation of parameter mismatch in Figure 8 is the same as that in Figure 7. The reference speed of the motor is increased from $900 \mathrm{r} / \mathrm{min}$ 
to $1500 \mathrm{r} / \mathrm{min}$ in a short time. It can be seen that the robust FCS-MPCC can also ensure accurate speed and current tracking performance.

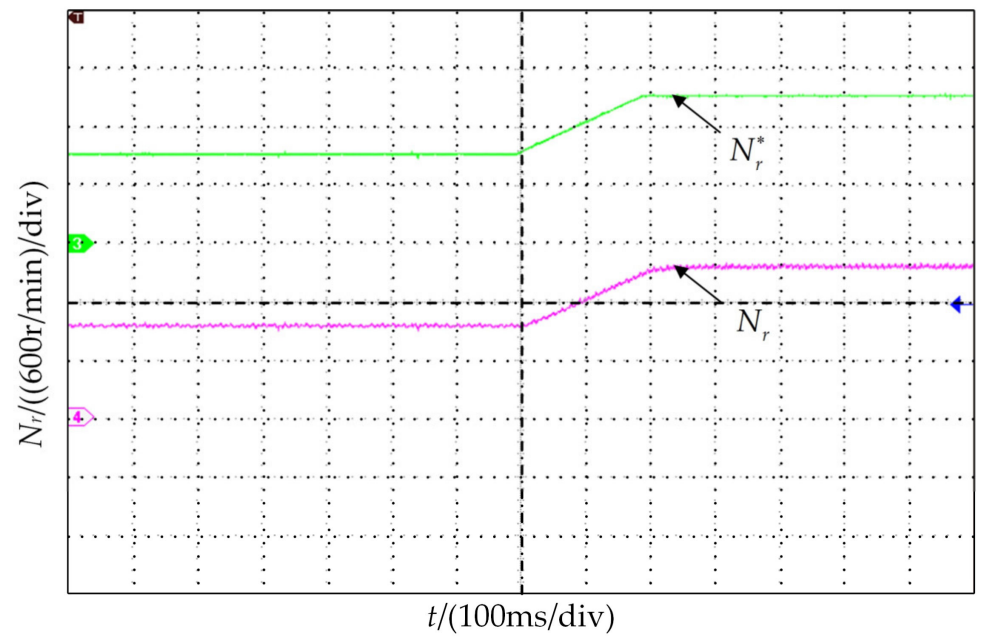

(a)

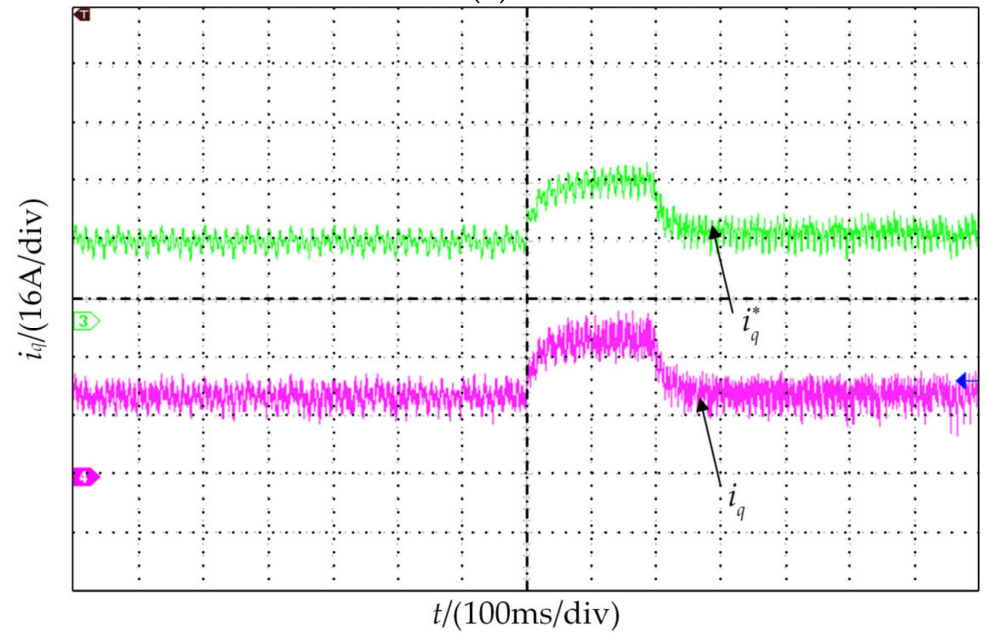

(b)

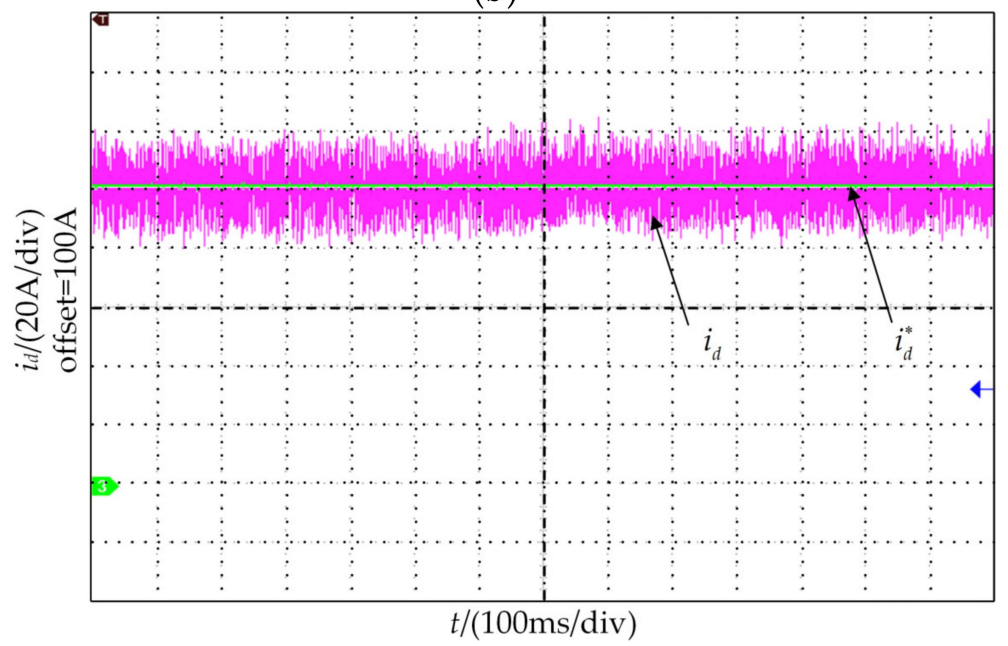

(c)

Figure 8. The speed and current transient responses of the robust FCS-MPCC under parameter mismatch. (a) speed; (b) $q$-axis current; (c) $d$-axis current. 
The current transient response of the robust FCS-MPCC under parameter mismatch is shown in Figure 9. The situation of parameter mismatch in Figure 9 is the same as that in Figures 7 and 8 . The speed keeps $900 \mathrm{r} / \mathrm{min}$ through the load motor to observe the current transient performance of the test IPMSM. The $q$-axis reference current changes from $25 \mathrm{~A}$ to $50 \mathrm{~A}$ and $d$-axis reference current keeps 0 in Figure $9 \mathrm{a}$, and the $d$-axis reference current changes from 0 to $-20 \mathrm{~A}$ and $q$-axis reference current keeps $25 \mathrm{~A}$ in Figure $9 \mathrm{~b}$. It shows that the robust FCS-MPCC has fast current transient response under parameter mismatch.

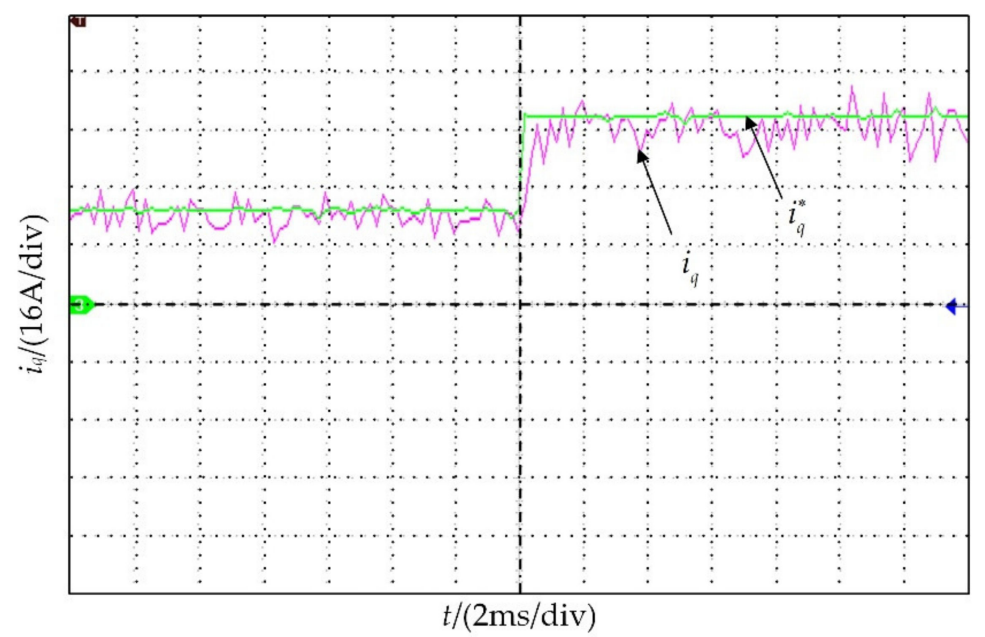

(a)

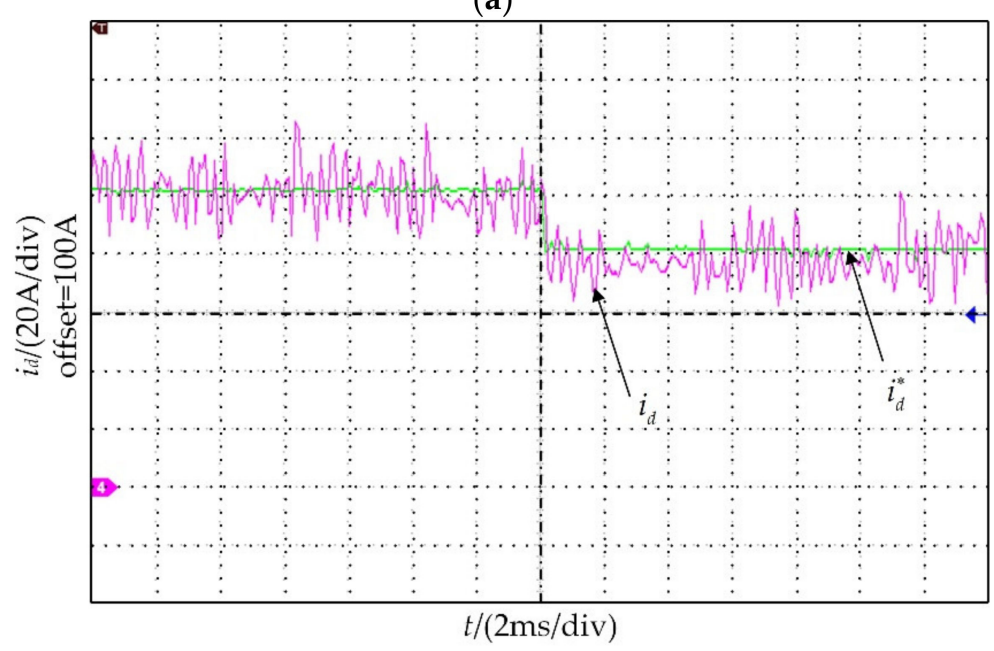

(b)

Figure 9. The current transient response of the robust FCS-MPCC under parameter mismatch. (a) $q$-axis current; (b) $d$-axis current.

\section{Conclusions}

Aiming at the problem that the control performance of conventional FCS-MPCC is easily affected by model parameters, a robust FCS-MPCC method is proposed in this paper. The structure of the new method is simple and it is easy to implement. The experimental results show that the proposed method can effectively reduce the current ripple, reduce the current distortion and improve the current tracking performance under parameter mismatch. The effectiveness of the proposed method is verified.

Author Contributions: Z.L. proposed the new method. Z.L. and X.W. conducted the simulation and experiments. Z.L. wrote the first draft. X.W., J.G. and G.T. guided and revised the manuscript. All authors have read and agreed to the published version of the manuscript. 
Funding: The project is partly supported by the National Natural Science Foundational of China (Grant number: 52007190) and partly supported by the Natural Science Foundational of Jiangsu Province (Grant number: BK20200652).

Institutional Review Board Statement: Not applicable.

Informed Consent Statement: Not applicable.

Data Availability Statement: None.

Conflicts of Interest: The authors declare no conflict of interest.

\section{References}

1. Erdiwansyah; Mahidin; Husin, H.; Nasaruddin; Zaki, M.; Muhibbuddin. A critical review of the integration of renewable energy sources with various technologies. Prot. Control. Mod. Power Syst. 2021, 6, 37-54. [CrossRef]

2. Golesorkhie, F.; Yang, F.; Vlacic, L.; Tansley, G. Field oriented control-based reduction of the vibration and power consumption of a blood pump. Energies 2020, 13, 3907. [CrossRef]

3. Nasr, A.; Gu, C.; Bozhko, S.; Gerada, C. Performance enhancement of direct torque-controlled permanent magnet synchronous motor with a flexible switching table. Energies 2020, 13, 1907. [CrossRef]

4. Wang, X.; Wang, Z.; Xu, Z.; Cheng, M.; Hu, Y. Optimization of torque tracking performance for direct-torque-controlled PMSM drives with composite torque regulator. IEEE Trans. Ind. Electron. 2020, 67, 10095-10108. [CrossRef]

5. Vadivel, R.; Joo, Y.H. Reliable fuzzy $\mathrm{H}_{\infty}$ control for permanent magnet synchronous motor against stochastic actuator faults. IEEE Trans. Syst. Man Cybern. Syst. 2021, 51, 2232-2245. [CrossRef]

6. Solsona, J.; Valla, M.; Muravchik, C. Nonlinear control of a permanent magnet synchronous motor with disturbance torque estimation. IEEE Trans. Energy Convers. 2020, 15, 163-168. [CrossRef]

7. Han, Y.; Gong, C.; Yan, L.; Wen, H.; Wang, Y.; Shen, K. Multiobjective Finite control set model predictive control using novel delay compensation technique for PMSM. IEEE Trans. Power Electron. 2020, 35, 11193-11204. [CrossRef]

8. Ahmed, A.A.; Kim, J.-S.; Lee, Y.I. Model predictive torque control of PMSM for EV drives: A comparative study of finite control set and predictive dead-beat control schemes. In Proceedings of the 2016 Eighteenth International Middle East Power Systems Conference (MEPCON), Cairo, Egypt, 27-29 December 2016; pp. 156-163.

9. Yang, T.; Kawaguchi, T.; Hashimoto, S.; Jiang, W. Switching sequence model predictive direct torque control of IPMSMs for EVs in switch open-circuit fault-tolerant mode. Energies 2020, 13, 5593. [CrossRef]

10. Gong, C.; Hu, Y.; Ma, M.; Yan, L.; Liu, J.; Wen, H. Accurate FCS model predictive current control technique for surface-mounted PMSMs at low control frequency. IEEE Trans. Power Electron. 2020, 35, 5567-5572. [CrossRef]

11. Gao, J.; Gong, C.; Li, W.; Liu, J. Novel compensation strategy for calculation delay of finite control set model predictive current control in PMSM. IEEE Trans. Ind. Electron. 2019, 67, 5816-5819. [CrossRef]

12. Wang, X.; Fang, X.; Lin, S.; Lin, F.; Yang, Z. Predictive common-mode voltage suppression method based on current ripple for permanent magnet synchronous motors. IEEE J. Emerg. Sel. Top. Power Electron. 2019, 7, 946-955. [CrossRef]

13. Chen, J.; Qin, Y.; Bozorgi, A.M.; Farasat, M. Low Complexity dual-vector model predictive current control for surface-mounted permanent magnet synchronous motor drives. IEEE J. Emerg. Sel. Top. Power Electron. 2020, 8, 2655-2663. [CrossRef]

14. Liu, X.; Zhou, L.; Wang, J.; Gao, X.; Li, Z.; Zhang, Z. Robust Predictive current control of permanent-magnet synchronous motors with newly designed cost function. IEEE Trans. Power Electron. 2020, 35, 10778-10788. [CrossRef]

15. Wang, L.; Tan, G.; Meng, J. Research on model predictive control of IPMSM based on adaline neural network parameter identification. Energies 2019, 12, 4803. [CrossRef]

16. Yuan, X.; Zhang, S.; Zhang, C. Nonparametric predictive current control for PMSM. IEEE Trans. Power Electron. 2020, 35, 9332-9341. [CrossRef]

17. Kang, S.; Soh, J.; Kim, R.; Lee, K.; Kim, S. Robust predictive current control for IPMSM without rotor flux information based on a discrete-time disturbance observer. IET Electr. Power Appl. 2019, 13, 2079-2089. [CrossRef]

18. Yuan, X.; Zhang, S.; Zhang, C. Enhanced robust deadbeat predictive current control for PMSM Drives. IEEE Access 2019, 7, 148218-148230. [CrossRef]

19. Jia, C.; Wang, X.; Liang, Y.; Zhou, K. Robust current controller for IPMSM drives based on explicit model predictive control with online disturbance observer. IEEE Access 2019, 7, 45898-45910. [CrossRef]

20. Lyu, M.; Wu, G.; Luo, D.; Rong, F.; Huang, S. Robust nonlinear predictive current control techniques for PMSM. Energies 2019, 12, 443. [CrossRef]

21. Wang, J.; Wang, F.; Wang, G.; Li, S.; Yu, L. Generalized proportional integral observer based robust finite control set predictive current control for induction motor systems with time-varying disturbances. IEEE Trans. Ind. Inform. 2018, 14, 4159-4168. [CrossRef] 